\title{
Pentingnya Mempelajari Administrasi Dan Supervisi Pendidikan Serta Konsep Profesi dan Tenaga Kependidikan
}

\author{
Nadya Olivia Perrina \\ Universitas Negeri Padang \\ Indonesia \\ E-mail: nadyaolivia2509.no@gmail.com
}

\begin{abstract}
Abstrak----Educational administration is the overall process of all joint activities that must be carried out by all parties concerned with educational tasks. Educational administration is also often termed school administration and the administration itself covers arrangements, teaching and learning processes, student affairs, personnel, teaching equipment, buildings and equipment, finance and public relations or community relations which are all included in educational administration.
\end{abstract}

Keywords---Administrative, process, education,
definition

\section{PENDAHULUAN}

Administrasi pendidikan merupakan proses keseluruhan dari segala kegiatan-kegiatan bersama yang harus dilakukan oleh semua pihak yang ada sangkut pautnya dengan tugas-tugas pendidikan. Administrasi pendidikan juga sering diistilahkan dengan administrasi sekolah dan administrasi itu sendiri mencangkup pengaturan, proses belajar mengajar, kesiswaan, personalia, peralatan pengajaran, gedung dan perlengkapan, keuangan serta humas atau hubungan dengan masyarakat yang ini semua merupakan cangkupan dari administrasi pendidikan.

Setiap aktivitas besar atau pun kecil, yang tercapainya tergantung kepada beberapa orang, di perlukan adanya koordinasi di dalam segala gerak langkah. Untuk mengkoordinasi semua gerak langkah tersebut pimpinan sekolah harus berusaha mengetahui keseluruhan sistuasi di sekolahnya dalam segala bidang.

Usaha Pimpinan dan guru untuk mengetahui situasi lingkungan sekolah dalam segala kegiatannya disebut supervisi atau pengawasan sekolah. Istilah supervisi ini kiranya belum begitu lajim dipergunakan dalam lingkungan persekolahan dan kepegawaian kita di saat sekarang, tetapi makin lama makin dikenal dan makin banyak di pergunakan orang. Namun demikian mengenai arti, fungsi dan tujuan yang terkandung di dalamnya masih merupakan tanda tanya. Apakah sudah benar-benar di pahami oleh yang mempergunakan istilah itu.

\section{METODE PENELITIAN}

Pada artikel ini, peneliti menggukan metode Systematic Literature Review (SLR), maksudnya dengan cara terlebih dahulu mengumpulkan bahan-bahan berupa kajian atau rujukan terkait administrasi pendidikan baik berupa buku, artikel, jurnal, makalah dan sumber lainnya. Setelah bahan kajian dikumpulkan, kemudian bahan tersebut dipelajari, selanjutnya penulis berusaha menyimpulkan sebuah pengetahuan baru hasil dari analisis terhadap bahan kajian atau rujukan tersebut studi literatur dengan cara mengumpulkan literatur (bahan-bahan materi) yang bersumber dari buku, artikel, jurnal, makalah dan sumber lainnya terkait ilmu tentang Administrasi Pendidikan.

\section{KAJIAN TEORI DAN PEMBAHASAN}

\section{Pengertian administrai pendidikan}

Secara etimologi, kata administrasi berasal dari bahasa latin ad dan administrare yang menurut Gei (1992) artinya melayani, membantu, menunjang, pencapaian tujuan sehingga benar-benar tercapai. Selanjutnya Siagian (1986) mendefinisikan administrasi sebagai keseluruhan proses kerjasama antara dua orang atau lebih yang didasarkan atas rasional tertuntu untu mencapai tujuan yang telah didtetapkan sebelumnya. Nurhadi (1983) mengartikan administrasi sebagai suatu kegiatan atau rangkaian kegiatan yang berupa proses pengelolaan usaha kerjasama sekelompok manusia yang tergabing dalam suatu organisasi untuk mencapai tujuan bersama yangtelah ditetapkan sebelumnya agar efektif dan efesien.

Dari definisi diatas maka administrasi dapat diuraikan menjadi 5 pengertian pokok yaitu:

a. administrasi merupakan kegiatan atau rangkaian kegiatan manusia 
b. rangkaian kegiatan itu merupakan suatu proses dan bersifat dinamis

c. prose situ dillakukan bersama oleh sekelompok manusia yang tergabung dalam suatu organisasi.

d. Proses itu dilakukan dalam rangka mencapai suatu tujuan yang telah ditetapkan sebelumnya

e. Proses pengelolan itu dilakukan agar tujuan dicapai secara efektif dan efisien.

\section{Perlunya administrsi pendidikan}

Adminisrasi pendidikan merupakan subsistem dari system pendidikan disekolah yang bertujuan menunjang pencapaian tujuan pendidikan secara efektif dan efisien. Komponen utama dalam system pendidikan yang memegang peranan penting dalam pencapaian tujuan pendidikan adalah guru. Oleh karena itu guru mempunyai peranan penting dalam administrasi pendidikan terutama dalam melaksanakan fungsi pokok administrasi.

Dalam PP 38 Tahun 1992 Pasal 20 dikatakan bahwa tenaga pendidik yang ditugas kan untuk menjadi pengelola satuan pendidikan dan pengawasan pada jenjang pendidikan dasar adalah dari kalangan guru. Oleh karena itu pengembangan karir guru berkaitan dengan bidang administrasi pendidikan. Berdasarkan hal-hal tersebut calon-calon guru yang akan bertugas sebagai pengajar, harus memperoleh latar belakang pengetehuan dan keterampilan dalam administrasi pendidikan.

\section{Pengertian Supervisi}

Inspeksi berasal dari istilah bahasa Belanda Inspectie. Di dalam bahasa Inggris dikenal Inspection. Kedua kata tersebut berarti pengawasan yang terbatas kepada pengertian mengawasi apakah bawahan (dalam hal ini guru) menjalankan apa yang telah diinstruksikan oleh atasannya, dan bukan berusaha membantu guru itu (Ngalim Purwanto, 1990).

Dalam perkembangan supervisi selanjutnya dikenal istilah penilikan dan pengawasan. Berbeda dengan inspeksi, penilikan dan pengawasan mempunyai pengertian suatu kegiatan yang bukan hanya mencari kesalahan objek pengawasan itu semata-mata, tetapi juga mencari hal-hal yang sudah baik, untuk dikembangkan lebih lanjut.

Monitoring seringkali diterjemahkan ke dalam bahasa Indonesia dengan pemantauan. Monitoring berti kegiatan pengumpulan data tentang suatu kegiatan sebagai bahan untuk melaksanakan penilaian. Dengan kalimata ini, monitoring merupakan kegiatan yang ditujukan untuk mengetahui apa adanya tentang sesuatu kegiatan. Di dalam monitoring seseorang hanya mengumpulkan data tanpa membandingkan data tersebut dengan kriteria tertentu.Kegiatan penilaian, yang juga disebut evaluasi merupakan suatu proses membandingkan keadaan kuantitatif atau kualitatif suatu objek dengan kriteria tertentu yang sudah ditetapkan sebelumnya.

Pengertian supervisi mencakup arti yang terkandung dalam istilah-istilah yang sudah ada diterangkan itu. Di samping itu, supervisi memepunyai arti yang lebih luas, yaitu pengertian, bantuan dan perbaikan.Berbagai buku mendefinisikan supervisi berbeda satu sama lain. Daresh (1989), misalnya mendefinisikan supervisi sebagai suatu proses mengawasi kemampuan seseorang untuk mencapai tujuan organisasi. Wiles (1955) mendefinisikannya sebagai bantuan dalam pengembangan situasi belajar-mengajar Lucio dan McNeil (1978) mendefinisikan tugas supervisi, yang meliputi:

a. Tugas perencanaan, yaitu untuk menetapkan kebijaksanaan dan program.

b. Tugas administrasi, yaitu pengambilan keputusan serta pengkoordinasian melalui konferensi dan konsultasi yang dilakukan dalam usaha mencari perbaikan kualitas pengajaran.

c. Partisipasi secara langsung dalam pengembangan kurikulum, yaitu dalam kegiatan merumuskan tujuan, membuat penuntun mengajar bagi guru, dan memilih isi pengalaman belajar.

d. Melaksanakan demonstrasi mengajar untuk guru-guru, serta

e. Melaksanakan penelitian.

Sergiovanni dan Starratt berpendapat bahwa tugas utama supervisi adalah perbaikan situasi pengajaran.Dari berbagai definisi tersebut, kelihatannya ada kesepakatan umum, bahwa kegiatan supervisi pengajaran ditujukan untuk perbaikan pengajaran.Perbaikan itu dilakukan melalui peningkatan kemampuan profesional guru dalam melaksanakan tugasnya.

\section{Pengertian Pendidik}

Pendidik merupakan tenaga profesional yang bertugas merencanakan dan melaksanakan proses pembelajaran, menilai hasil pembelajaran, melakukan pembimbingan dan pelatihan, serta melakukan penelitian dan pengabdian kepada 
masyarakat, terutama bagi pendidik pada perguruan tinggi. (UU No.20 THN 2003, PSL 39 (2))

Misalnya:
a. tenaga profesional
b.merencanakan pembelajaran.
c. melaksanakan pembelajaran.
d.menilai hasil pembelajaran.
e. membimbing
f. melatih
g. meniliti
h. mengabdi kepada masyarakat.

seperti:

Guru,Dosen,Tutor,Instruktur,Pamong ,Konselor,Wi dyaiswara,Fasilitator,Penguji,Dst.

\section{Tenaga kependidikan}

Ketentuan umum) Tenaga kependidikan adalah anggota masyarakat yang mengabdikan diri dan diangkat untuk menunjang penyelenggaraan pendidikan. (UU No. 20 tahun 2003 psl 1, BAB 1. Merupakan tenaga yang bertugas merencanakan dan melaksanakan administrasi, pengelolaan, pengembangan, pengawasan, dan pelayanan teknis untuk menunjang proses pendidikan pada satuan pendidikan. (UU No.20 THN 2003, PSL 39 (1)). Menurut perundang-undangan yang berlaku di Indonesia, yaitu Undang-Undang Sistem Pendidikan Nasional No.20 Tahun 2003, khususnya Bab I Pasal 1 ayat (5) menyebutkan bahwa tenaga kependidikan itu adalah anggota masyarakat yang mengabdikan diri dan diangkat untuk menunjang penyelenggarakan pendidikan.

Tenaga kependidikan merupakan seluruh komponen yang terdapat dalam instansi atau lembaga pendidikan yang tidak hanya mencakup guru saja melainkan keseluruhan yang berpartisipasi dalam pendidikan (mencakup tebaga edukatif dan administrative). Dilihat dari jenisnya tenaga kependidikan terdiri atas :

a. Tenaga kependidikan adalah anggota masyarakat yang mengabdikan diri dan diangkat untuk menunjang penyelanggaraan pendidikan. Tenaga kependidikan terdiri atas tenaga pendidik, pengelola satuan pendidikan, penilik, pengawas, peneliti, dan pengembang dalam bidang pendidikan, pustakawan, laboran, teknisi sumber belajar dan penguji. Pengelola satuan pendidikan bertugas dan mengelola satuan pendidikan pada pendidikan formal dan non formal. Penilik satuan pendidikan bertugas dan bertanggungjawab melakukan pembinaan, pembimbingan dan penilaian pada satuan pendidikan. Pengawas bertugas dan bertanggungjawab dalam melakukan pengawasan pendidikan terhadap pendidik atau penyelenggara satuan pendidikan taman kanak-kanak, dasar, dan menengah dengan melaksanakan penilaian dan pembinaan teknis pendidikan. Pustakawan bertugas melaksanakan pengelolaan sumber belajar di perpustakaan. Laboran bertugas melaksankan pengelolaan sumber belajar di laboratorium. Teknisi bertugas merawat, memperbaiki sarana dan prasarana pembelajaran pada satuan pendidikan

b. Tenaga pendidik adalah tenaga kependidikan yang berkualifikasi sebagai guru, dosen, konselor, pamong belajar, tutor, instruktur, fasilitator dsb yang sesuai dengan kekhususannya dan berpasttisipasi dalam menyelenggarakan pendidikan.

c. Pengelola satuan pendidikan terdiri atas kepala sekolah, direktur, ketua, rektor, pimpinan satuan pendidikan di luar sekolah. Termasuk pengelola sistem pendidikan seperti kepala kantor dinas pendidikan di tingkat provinsi atau kabupaten/kota.

Jadi, secara umum tenaga kependidikan dapat dibedakan menjadi empat kategori yaitu

a. Tenaga pendidik

Terdiri atas pembimbing, penguji, pengajar, dan pelatih.

b. Tenaga fungsional kependidikan

Terdiri atas penilik, pengawas, peneliti, dan pengembang di bidang pendidikan dan pustakawan.

c. Tenaga teknis kependidikan

Terdiri atas laboran dan teknisi sumber belajar.

d. Tenaga pengelola satuan pendidikan

Terdiri atas kepala sekolah, direktur, ketua, rektor, dan pemimpin satuan pendidikan luar sekolah.

\section{Pengertian jenis tenaga kependidikan}

a. Kepala Sekolah

Kepala Sekolah yaitu orang yang diberi wewenang dan tanggung jawab untuk memimpin satuan pendidikan tersebut. Kepala Sekolah harus mampu melaksanakan peran dan tugasnya sebagai edukator, manajer, administrator, supervisor, leader, inovator, motivator, figur dan mediator

b. Guru ( kelas, agama, penjaskes, muatan lokal ) 
Guru/pengajar, adalah tenaga kependidikan yang berpartisipasi dalam menyelenggarakan pendidikan dengan tugas khusus sebagai profesi pendidik.

c. Tenaga Administrasi / TU

Tata usaha adalah Tenaga Kependidikan yang bertugas dalam bidang administrasi instansi tersebut.

d. Penjaga Sekolah / kebersihan sekolah

e. Tenaga Fungsional lainnya ( Guru BP, Pustakawan, laboran dan teknisi sumber belajar)

Sedangkan apabila dilihat dari statusnya, tenaga kependidikan terdiri atas :

\section{a. Pegawai Negeri Sipil ( PNS )}

Pegawai Negeri Sipil (PNS) adalah salah satu jenis Kepegawaian Negeri di samping anggota TNI dan Anggota POLRI (UU No 43 Th 1999). Pengertian Pegawai Negeri adalah warga negara RI yang telah memenuhi syarat yang ditentukan, diangkat oleh pejabat yang berwenang dan diserahi tugas dalam suatu jabatan negeri, atau diserahi tugas negara lainnya, dan digaji berdasarkan peraturan perundang-undangan yang berlaku (pasal 1 ayat 1 UU 43/1999).

Berdasarkan uraian di atas, dapat disimpulkan bahwa konsep profesionalisme Pegawai Negeri Sipil harus memiliki ciri-ciri sebagai berikut:

a. Menguasai pengetahuan dibidangnya selalu berusaha dengan sungguh sungguh untuk mem-perdalam pengetahuannya dengan tujuan agar dapat melaksanakan tugasnya secara berdaya guna dan berhasil guna.

b. Komitmen pada kualitas

c. Dedikasi

d. Keinginan untuk membantu

\section{b. Guru tidak tetap}

a. GTT (Guru Tidak Tetap) Sekolah Negeri adalah istilah yang lazim "dicapkan" atau disebut oleh pihak sekolah untuk guru yang

1)Diangkat berdasarkan kebutuhan pada satuan pendidikan (sekolah) dengan disetujui kepala sekolah.

2)Kewenangan bertumpu kepada kepala sekolah, baik pengangkatan juga pemberhentian.

3)Menandatangani kontak kerja selama jangka waktu tertentu, setahun atau lebih sesuai dengan kebutuhan sekolah.
4)Dibiayai atau digaji berdasarkan sumbangan dari masyarakat dan tunjangan fungsional Rp.200.00/bulan, khusus yang memenuhi kuota 24 jam dengan berbagai pertimbangan, baik itu jam mengajar dari beberapa sekolah, sebagai wali kelas, pembina ekskul, tim IT sekolah, staff, dan jabatan lainnya dalam koridor pendidikan.

5)Tunjangan fungsional adalah "jasa baik" Pemda, walaupun legal, akan tetapi tidak masuk dalam kategori dari "pembiayaan APBD".

6)GTT adalah guru yang tidak masuk anggaran APBN dan APBD.

\section{b.GTT adalah bukan Guru PTT (Pegawai Tidak Tetap)}

yang seringkali disamaartikan atau tersamarkan sebagai guru honor. Dalam terminologi legal yang berlaku di beberapa anggota DPR, surat kabar, dan Pemda, guru honor untuk menyebut Guru PTT. Dalam arti demikian, sekali lagi, GTT bukan Guru PTT.

\section{c.GTT sampai hari ini,}

belum memiliki payung hukum, baik dalam provinsi maupun nasional. Sehingga, pihak-pihak yang miskin hati nuraninya, dapat dengan mudah menyingkirkan GTT disatuan pendidikan, baik itu di sekolah negeri ataupun swasta. Namun, GTT yang berani dan cerdas, akan bergabung ke SGJ (Serikat Guru Jakarta) atau organisasi guru lainnya yang legal sebagai forum untuk berjuang demi pengakuan legal serta faktual. SGJ bahkan pernah dan tak akan berhenti membela GTT yang diberhentikan secara semena-mena, apalagi diluar ketentuan yang berlaku.

\section{d.GTT memiliki gaji yang kecil}

bila dibandingkan dengan PNS, yang secara jelas memiliki tanggungjawab sama. Kenyataan ini, seringkali memunculkan kecemburuan yang rasional dan realistis. Pemegang kebijakan, provinsi dan nasional, sedang mengusahakan perbaikan gaji, karena mereka menyadarinya. Semoga bukan karena tekanan yang selama kurang lebih 3 tahun ini dilakukan oleh SGJ.

\section{e.GTT termasuk guru yang kurang peduli,}

dan kurang semangat dalam menyuarakan kepentingan mereka, kecuali kalau sudah terancam, baik itu diberhentikan, dikurangi jam mengajar, atau dipersilahkan untuk keluar dari sekolah negeri. Maka, GTT harus bersatu, kompak.

\section{c. Guru bantu}


Guru nonPNS yang berkedudukan sebagai pegawai Departemen Pendidikan Nasional Pusat, ditugaskan secara penuh di sekolah dan pengangkatannya dilakukan melaui program pengadaan guru bantu, berdasarkan kontrak kerja selama 3 tahun. Masing-masing guru bantu mendapat upah sebesar Rp. 460.000,00 yang diambil dari APBN.

\section{d. Tenaga sukarela}

Merupakan tenaga kependidikan nonguru yang memiliki honor yang relative kecil. Di tingkat sekolah menengah, pengelolaan secara admisintratif, personel (kepegawaian) ada pada urusan tata usaha atas wewenang yang diberikan oleh kepala sekolah, sedang di sekolah dasar, semua urusan dipegang oleh kepala sekolah.

\section{KESIMPULAN}

Administrasi pendidikan bertujuan untuk mencapai tujuan pendidikan. Pengertian administrasi pendidikan dapat dirumuskan dari berbagai sudut pandang, seperti kerjasama, proses kerjasama, sistem dan mekanismenya manajemen, kepemimpinan proses pengambilan keputusan, komunikasi dan ketatausahaan. Lingkup pembicaraan tentang administrasi pendidikan itu juga tergantung pada level tujuan pendidikan yang ingin dicapai, yaitu pada tingkat kelas dampai pada tingkat sistem pendidikan nasional. Makin luas cakupannya makin banyak yang terlibat dan makin komplek permasalahannya.

Supervisi pendidikan adalah Suatu aktivitas pembinaan terencana yang berorientasi kepada Guru dan Pegawai sekolah Secara efektif . Pada hakekatnya tujuan supervise adalah memperbaiki atau meningkatkan proses belajar mengajar. Fungsi supervise dapat disimpulkan sebagi alat untuk menungkatkan kulaitas dan kuantitas kepada semua pihak yang berhubungan dengannya dan melestarikannya

\section{Daftar Pustaka}

Ngalim purwanto, M.2010. Administrasi dan Supervisi Pendidikan. Bandung: PT Remaja Rosdakarya.

Purwanto, Ngalim.1998. Administrasi dan Supervisi Pendidikan, Bandung: PT Remaja Rosdakarya.

Undang-Undang Sistem Pendidikan Nasional No.20 Tahun 2003 